\title{
Pendampingan Pendokumentasian dan Penulisan Sejarah Keluarga di Desa Beji, Ngawen, Gunung Kidul
}

\author{
Mutiah Amini, Uji Nugroho Winardi, Wildan Sena Utama, Bambang Purwanto, \\ Abdul Wahid, Arif Akhyat, dan Farabi Fakih
}

Departemen Sejarah, Fakultas Ilmu Budaya, Universitas Gadjah Mada

Korespondensi: mutiah.a@ugm.ac.id

\begin{abstract}
The Department of History conducted a community service (PkM) on the topic of documenting and writing family history in Beji Village, Ngawen, Gunung Kidul. The PkM activities are conducted by lecturers and students of History in six months in 2019. Writing and documenting family history is carried out in a participatory method by a coloboration with village residents. The PkM activities were carried out in three stages. First, on May 4, 2019 a dialogue was held between the PkM team and the village stakeholders regarding the plan to write and document the family history of Beji Village. Secondly, on July 15, 2019 the PkM team observed the Nyadran process held by the Beji Village community. Third, the PkM team provides assistance in writing family history and documenting important figures who intersect with culture and art, cultural traditions, and multicultural identities in Beji Village. At the end of this PkM activity, a family history of the village leader has produced, namely the family history of Mbah Yatmo, a prayer reader at the Sadranan ceremony in Beji Village.
\end{abstract}

Keywords: History; family; documentation; accompaniment; Beji

\begin{abstract}
Abstrak
Departemen Sejarah melakukan pengabdian kepada masyarakat $(\mathrm{PkM})$ dengan topik pendokumentasian dan penulisan sejarah keluarga di Desa Beji, Ngawen, Gunung Kidul. Seluruh kegiatan PkM dilakukan oleh dosen dan mahasiswa Ilmu Sejarah dalam waktu enam bulan pada tahun 2019. Penulisan serta pendokumentasian sejarah keluarga yang dilakukan secara partisipatif bersama warga. Kegiatan PkM tersebut dilaksanakan dalam tiga tahapan kegiatan. Pertama, pada 4 Mei 2019 diadakan dialog antara tim PkM dan pemangku desa mengenai rencana penulisan dan pendokumentasian sejarah keluarga Desa Beji. Kedua, pada 15 Juli 2019 tim PkM melakukan observasi proses Nyadran yang diselenggarakan oleh masyarakat Desa Beji. Ketiga, tim PkM melaksanakan pendampingan penulisan sejarah keluarga dan pendokumentasian tokoh penting yang bersinggungan dengan kebudayaan dan kesenian, tradisi kultural, dan identitas multikultural di Desa Beji. Pada akhir kegiatan PkM ini dihasilkan contoh penulisan sejarah keluarga tokoh desa, yaitu sejarah keluarga Mbah Yatmo, seorang pembaca doa dalam upacara Sadranan di Desa Beji.
\end{abstract}

Kata Kunci: Sejarah; keluarga; dokumentasi; pendampingan; Beji

\section{Pendahuluan}

Secara historis, Beji memiliki karakteristik wilayah yang unik. Wilayah ini merupakan salah satu wilayah enklave, yaitu sebagai wilayah Kasunanan yang berada di wilayah 
Kasultanan Yogyakarta (Sulistyowati, 2015). Sebagai penanda bahwa wilayah ini merupakan wilayah enklave, dibuatlah gapura tapal batas berupa Tugu Mataram sebagai pembatas wilayah ini dengan wilayah lainnya. Keberadaan wilayah enklave di dalam Kasultanan Yogyakarta menjadikan wilayah ini memiliki kekayaan kultural yang unik. Sebagian dari kekayaan kultural tersebut berkiblat ke Surakarta. Sebagian yang lain berkiblat ke Yogyakarta. Kontestasi antara kultur Yogyakarta dan Surakarta masih bertahan hingga saat ini. Kearifan lokal masyarakat tempatanlah yang mampu menjadikan kontestasi menjadi kekuatan untuk menciptakan harmoni yang tetap terpelihara hingga saat ini.

Selain kekayaan kultural sebagai sebuah wilayah enklave, Beji juga menyimpan jejakjejak historis yang sangat beragam. Berbagai peninggalan masa lalu dijaga oleh masyarakat ini dan bahkan sebagian di antaranya dikeramatkan, seperti Watu Gendong, Sendang, dan Hutan Wonosadi. Masyarakat Beji menjaga seluruh jejak historis tersebut dengan baik. Berbagai mitos terkait dengan ikatan masa lalu mereka dengan Kerajaan Majapahit terpelihara secara turun-temurun. Puncak dari kesadaran terhadap pemeliharan jejakjejak masa lalu tersebut selanjutnya diabadikan dalam sebuah upacara Sadranan yang diselenggarakan setahun sekali (Amini dkk., 2017). Upacara ini merupakan salah satu bentuk pelestarian alam, yang menurut masyarakat Beji merupakan pesan dari leluhur. Dengan pelestarian hutan dipercaya seluruh masyarakat Beji akan terbebas dari bencana dan selalu berada di dalam kemakmuran.

Berbagai mitos yang berkembang tentang kesakralan tempat-tempat bersejarah di Beji, terbukti mampu menciptakan kesuburan alam di wilayah ini. Pada tahun 1960an, Desa Beji pernah mengalami kerusakan alam yang sangat dahsyat akibat peristiwa 30 September 1965 karena alam dipergunakan sebagai alat untuk propaganda politik beberapa organisasi politik ketika itu (Ibrahim, 2012). Berkat cerita masa lalu tentang pentingnya menjaga alam desa, pada tahun 1970-an, Desa Beji kemudian kembali menjadi desa yang subur. Karena kesuburuan alam yang tercipta sejak tahun tersebut, penghargaan penting pernah diraih desa ini (Laksono, 2009). Pada tahun 2009, salah seorang penggiat kesuburan alam Desa Beji memperoleh "Kehati Award" untuk kategori "Prakarsa Lestari Kehati".

Saat ini, masyarakat Desa Beji terus memelihara kesuburan alam melalui penciptaan kesenian-kesenian desa yang bernuansa alam. Berbagai dusun menciptakan seni budaya masing-masing, seperti Rinding Gumbeng, Gejok Lesung dan Tek-tek Bambu Laras. Seluruh kesenian yang dikembangkan yang terkait erat dengan pemeliharaan alam dan masa lalu desa pada akhirnya memberikan potensi yang sangat besar untuk dikembangkan menjadi desa wisata yang unggul, dengan memperhatikan kekayaan kultural desa. Oleh karena itu, Pengabdian kepada Masyarakat $(\mathrm{PkM})$ yang terprogram menjadi penting dilakukan di Desa Beji agar potensi yang dimiliki dapat berkembang lebih terencana dan terprogram.

Dalam konteks ini, sejarah keluarga di Desa Beji, Ngawen akan memiliki arti penting, baik bagi masyarakat Beji sendiri maupun bagi perkembangan bidang Ilmu Sejarah. Arti penting penulisan dan pendokumentasian sejarah keluarga dapat diuraikan sebagai berikut. Pertama, identitas masyarakat enklave yang kompleks. Beji yang merupakan bagian dari Kecamatan Ngawen merupakan wilayah enklave yang secara kultural bersifat kompleks, terutama karena adanya sekat-sekat sosial yang berakar 
dari perbedaan budaya. Dalam kompleksitas itu, keluarga merupakan institusi yang memainkan peran penting dalam menyambung hubungan interpersonal sehingga terbangun masyarakat yang integratif. Melalui penulisan dan pendokumentasian sejarah keluarga, program ini diharapkan dapat menemukan lebih banyak lagi identitas integral yang mempersatukan masyarakat di luar ikatan formalistik Desa Beji sebagai suatu kesatuan unit administrasi.

Kedua, sosial engineering. Sejarah keluarga yang dikerjakan bersama-sama bernilai penting sebagai suatu rekayasa sosial yang menggunakan masa lalu bersama untuk memperkuat kerja sama antarwarga. Dengan menggunakan sejarah keluarga, program ini ingin menciptakan ruang-ruang interaksi alternatif bagi masyarakat yang dapat berdaya guna dalam berbagai bidang, seperti rekonsiliasi sosial, revitalisasi tradisi, dan ingatan sosial, hingga berguna praktis, misalnya untuk pembangunan.

Ketiga, masa lalu yang aktual. Urgensi program ini tidak luput dari agenda besar dalam perkembangan Ilmu Sejarah di Indonesia yang berusaha menemukan alternatifalternatif baru dalam melihat peran penting pada masa lalu untuk masa kini (Purwanto, 2008). Penulisan serta pendokumentasian sejarah keluarga dilakukan secara partisipatif bersama warga.

\section{Pendekatan Pelaksanaan Program}

Kegiatan PkM di Desa Beji akan dilakukan dalam jangka waktu enam bulan dengan tahapan yang secara garis besar dapat diuraikan sebagai berikut. Tahap pertama fokus pada "Pengenalan Diri Sendiri untuk Menghasilkan Karya Sejarah Keluarga". Tahap kedua fokus pada "Pendampingan Penulisan Sejarah Keluarga". Seluruh kegiatan pengabdian dilakukan oleh dosen dan mahasiswa Ilmu Sejarah. Dosen program studi Ilmu Sejarah bertanggung jawab untuk melakukan pendampingan secara bertahap dari setiap target kegiatan yang telah dijadwalkan. Dukungan dari mahasiswa juga dilakukan di dalam kegiatan ini untuk mempermudah jalinan komunikasi antara dosen dan masyarakat tempatan. Review atas berjalannya kegiatan ini akan dilakukan setiap bulan sehingga dalam jangka waktu 6 bulan seperti yang dijadwalkan, outcome yang dirasakan oleh masyarakat tempatan dapat dilihat, terutama dalam bentuk tulisan sejarah yang ditulis bersama-sama.

Dalam hal penulisan sejarah, pengumpulan sumber dilakukan secara kolaboratif, baik dengan menggunakan interview, studi literatur, koran, dan dokumen lainnya. Pada tahap ini, dosen dibantu mahasiswa akan terlibat sebagai fasilitator dan pendamping pengumpulan sumber yang mayoritas pengerjaannya oleh tim lokal. Setelah sumber terkumpul, langkah selanjutnya adalah verifikasi, kritik, dan penulisan. Pada tahap penulisan ini, tim akan melakukan pendampingan dalam penyusunan naskah.

\section{Pelaksanaan Program}

\section{Mengenal Kekuatan Desa}

Sejarah keluarga merupakan salah satu topik yang masih belum banyak dieksplorasi dalam historiografi Indonesia. Fakta tersebut menjadi sebuah realitas yang dihadapi 
ketika tim PkM Departemen Sejarah melakukan pengabdian masyarakat dengan topik pendokumentasian dan penulisan sejarah keluarga di Desa Beji, Ngawen, Gunung Kidul ini. Di sebuah desa yang menyimpan narasi sejarah yang kompleks, warisan heritage yang lestari, dan identitas kultural yang multiragam dan menarik, tentu menulis sejarah sosial dengan berangkat dari pengalaman-pengalaman keluarga di Desa Beji sangat bermanfaat. Melalui pengalaman-pengalaman keluarga, kita dapat belajar, misalnya, mengenai bagaimana warisan kultural di sana tetap berlangsung dan beradaptasi dengan modernisme dan juga bagaimana merawat keberagaman di dalam masyarakat multikultural seperti di Desa Beji.

Desa Beji terkenal dengan warisan kulturalnya yang masih dilaksanakan oleh masyarakat di sana untuk merawat memori kolektif komunitas di sana-terlepas dari adanya pengaruh mitologisasi dalam memori kolektif tersebut-misalnya, dalam tradisi Nyadran yang rutin diselenggarakan setiap tahun di Hutan Wonosadi. Prosesi ini dilakukan dengan membawa hasil bumi dan makanan tradisional setempat oleh masyarakat Beji dengan cara berjalan kaki menuju sebuah bukit di Hutan Wonosadi. Ritual ini diselenggarakan sebagai medium cara bagaimana masyarakat menghormati arwah para leluhur yang telah menemukan dan mendirikan "permukiman" awal di daerah tersebut. Dengan prosesi kultural seperti Nyadranan tersebut masyarakat akan mengingat proses awal mula "kelahiran" mereka dan juga bagaimana mereka mensyukuri kehidupan mereka hingga hari ini. Dalam tradisi Nyadranan terdapat percampuran secara sinkretis antara tradisi Jawa, pengaruh Hindu, dan juga Islam. Hal ini memperlihatkan bagaimana secara historis sebuah tradisi kebudayaan bertransformasi menjadi kompleks dengan menyerap unsur-unsur keagamaan, sosial, dan budaya yang terdapat di daerah itu.

Mengenai keanekaragaman, Desa Beji juga terdiri atas masyarakat yang multikultur. Ada latar belakang Islam, Kristen Protestan, Katolik, Hindu, dan Kejawen yang tinggal dan berbaur. Konflik berlatar belakang identitas sangat jarang terjadi. Mereka dapat hidup harmonis, bertoleransi dengan perbedaan-perbedaan tersebut, dan hidup saling mengisi. Perbedaan adalah suatu keniscayaan dan sebuah kekuatan bukan sesuatu yang harus dihindari, direduksi menjadi suatu identitas yang homogen, dan juga dianggap sebagai kelemahan atau penghalang untuk berkembang. Di tengah problem akibat politik identitas, tentu latar belakang multikultural semacam ini menarik untuk dikaji dan dijadikan semacam medium untuk dipelajari secara ilmiah dan dijadikan bekal untuk mewujudkan suatu masyarakat multiidentitas yang bersatu. Kita tidak perlu merujuk pada pengalaman-pengalaman Barat atau negara luar nun jauh di sana karena pengalaman hidup berdampingan antaridentitas hidup di tengah-tengah masyarakat kita dan bisa dipelajari dari dekat.

Hal menarik ketiga yang ditemukan di Desa Beji adalah hingga hari ini, masyarakat mereka berusaha untuk mewariskan tradisi-tradisi kebudayaan dan kesenian kepada generasi selanjutnya. Di Desa Beji terdapat para pelaku kesenian tarian tradisional, dalang, pengrajin keris, dan seniman lainnya. Di tengah gempuran modernisme, tentu menjalankan profesi-profesi semacam ini dianggap melawan arah zaman. Namun, yang menarik adalah terjadi pewarisan terhadap tradisi, budaya, dan kesenian tersebut dari generasi seniman ke generasi-generasi selanjutnya dari para seniman di Desa Beji.

Fenomena-fenomena sosio-kultural seperti yang disebutkan di atas menarik minat tim $\mathrm{PkM}$ ini untuk menelusuri secara historis, misalnya, mengapa tradisi kultural 
masyarakat tetap hidup, mengapa identitas multikultural dapat berlangsung secara toleran, dan mengapa generasi seniman atau pelaku kebudayaan dapat terus bereproduksi. Cara yang dilakukan oleh tim penelitian ini sebenarnya cukup sederhana, yaitu menggali dan mengeksplorasi hal-hal tersebut melalui penelusuran atas sejarah keluarga di Desa Beji. Melalui penelusuran terhadap memori sejarah keluarga, diharapkan tim $\mathrm{PkM}$ mendapatkan informasi dan pengetahuan mengenai pertanyaan-pertanyaan di atas. Untuk merealisasikan ide tersebut, tim PkM dalam topik "Pendampingan Pendokumentasian dan Pendampingan Penulisan Sejarah Keluarga di Desa Beji" dilakukan dalam tiga tahapan kegiatan. Pertama, pada 4 Mei 2019, tim PkM yang berjumlah enam orang berangkat menuju Desa Beji, Ngawen, Gunung Kidul untuk menemui Kepala Desa Beji. Dalam pertemuan yang diadakan di Kantor Desa Beji, diadakan dialog antara tim PKM dan pemangku desa mengenai rencana penulisan serta pendokumentasian sejarah keluarga Desa Beji. Sebelumnya, Departemen Sejarah pernah melakukan pengabdian masyarakat di Desa Beji untuk menulis mengenai sejarah desa atau kampungnya sendiri dengan menggunakan perspektif masyarakat setempat. Penyampaian ide mengenai penulisan dan pendokumentasian sejarah keluarga di Desa Beji diterima dengan hangat oleh kepala desa. Ia menjelaskan sejarah dan folklor masyarakat Beji mengenai asal-usul desa tersebut dan menjelaskan heritage-heritage yang ada di desa tersebut. Ia menyambut ide untuk mendokumentasikan sejarah desa, tradisi kultural, kegiatan kebudayaan dan kesenian, serta identitas multikultural dengan menggunakan cara mewawancarai beberapa keluarga yang ada di Desa Beji.

Kedua, pada 15 Juli 2019, tim PkM mengikuti proses Nyadran yang diselenggarakan oleh kepala desa, sesepuh, tokoh budaya, dan masyarakat Desa Beji. Di dalam prosesi tersebut, tim mengikuti proses membawa hasil bumi dan makanan setempat ke Hutan Wonosadi. Setelah itu, tim PKM melakukan wawancara dengan keluarga juru kunci di Hutan Wonosadi yang telah pensiun karena sepuh. Wawancara yang dilakukan dalam bahasa Jawa berlangsung di rumah keluarga juru kunci. Dalam wawancara informal tersebut ditanyakan bagaimana proses menjadi juru kunci, apa yang dilakukan oleh juru kunci, bagaimana profesi juru kunci diwariskan, apa makna ritual Nyadran bagi masyarakat Beji, sampai cerita mengenai sejarah dan tradisi lisan Desa Beji. Wawancara informal itu didokumentasikan secara audio dan menjadi bahan yang berharga mendengar cerita langsung mengenai sejarah kebudayaan Beji dalam perspektif sejarah keluarga. Ketiga, tim PkM akan menyelenggarakan pendampingan penulisan sejarah keluarga dan pendokumentasian tokoh-tokoh penting yang bersinggungan dengan kebudayaan dan kesenian, tradisi kultural, dan identitas multikultural di Desa Beji. Kegiatan ini diharapkan dapat memicu keluarnya suara-suara yang bersumber dari masyarakat Beji, yang tentunya memiliki memori kolektifnya sendiri terhadap hal-hal tersebut. Dokumentasi visual akan dilakukan untuk menjadi semacam dokumenter yang merekam sejarah kebudayaan dan kesenian yang ada di Desa Beji. Hal ini penting dilakukan agar mereka dapat merekam narasi atau memori kolektif mereka ke dalam medium-medium lain yang mungkin lebih awet secara kontinuitas.

\section{Menyusun Sejarah Desanya Sendiri}

Pada kegiatan PkM sebelumnya, yaitu pada tahun 2017, dihasilkan sebuah buku yang ditulis oleh masyarakat Desa Beji yang berjudul Madeging Desa Beji. Buku ini ditulis 
oleh tiga orang penting di desa tersebut, yaitu Sumarno, Suparno, dan Tri Wijarno. Suparno adalah kepala desa saat ini. Sebelum mengabdikan diri sebagai kepala desa, Suparno merupakan seorang Pengawai Negeri Sipil (PNS) di Jakarta. Akan tetapi, setelah Suparno pensiun, ia merasa terpanggil untuk membawa kemajuan bagi desa tempat kelahirannya.

Kondisi seperti ini bukanlah hal yang baru di dalam kehidupan masyarakat Beji. Mayoritas usia aktif dalam masyarakat Beji biasanya merantau ke kota-kota besar, seperti Jakarta, Semarang, dan Surabaya. Kondisi desa yang tandus dan sulitnya mengembangkan pertanian di desa ini menjadi hal penting yang mendorong mereka untuk merantau. Beruntung sudah sejak beberapa tahun lalu Desa Beji mulai dikembangkan sebagai desa wisata karena kekayaan kultural yang dimiliki oleh desa ini. Bahkan, Dinas Kebudayaan dan Pariwisata kemudian memberikan perhatian khusus terhadap kekayaan yang dimiliki Desa Beji. Kekayaan yang ditinggalkan berupa heritage dan berbagai bentuk kesenian desa yang hingga saat ini masih terus dikembangkan dan diturunkan dari generasi ke generasi.

Buku Madeging Desa Beji merupakan satu bukti kesadaran masyarakat di Desa Beji untuk mengembangkan sejarah desa sekaligus untuk mengupayakan tetap lestarinya ingatan masa lalu masyarakat di desa tersebut. Buku ini ditulis dalam bahasa Jawa untuk memberikan kesadaran lokal dan menunjukkan bahwa hingga saat ini, bahasa Jawa masih menjadi fondasi berbahasa yang sangat penting dari Desa Beji. Aspek bahasa kemudian menjadi sangat penting, mengingat Desa Beji merupakan wilayah enklave. Akan tetapi, sebagai satu keputusan final yang kemudian dipilih, buku ini ditulis dengan menggunakan bahasa Jawa yang sepenuhnya menggunakan pitutur bahasa Jawa ala Kasultanan.

Secara garis besar, buku ini berisi beberapa hal berikut ini, yaitu Kademangan Ngawen, Tembung Beji, Watu Gendhong, Duren, Wonosadi lan Onggoloco, Madeging Desa Beji, Kepala Desa Beji, dan Jangka Kedah Jinangkah. Seperti tampak dalam isi, garis besar yang tertulis di dalam buku ini adalah mengenai sejarah desa dan identitas masa lalu yang kemudian dibangun. Tidak hanya terkait dengan Hutan Wonosadi, tetapi juga terkait dengan peninggalan-peninggalan masa lalu yang melengkapinya.

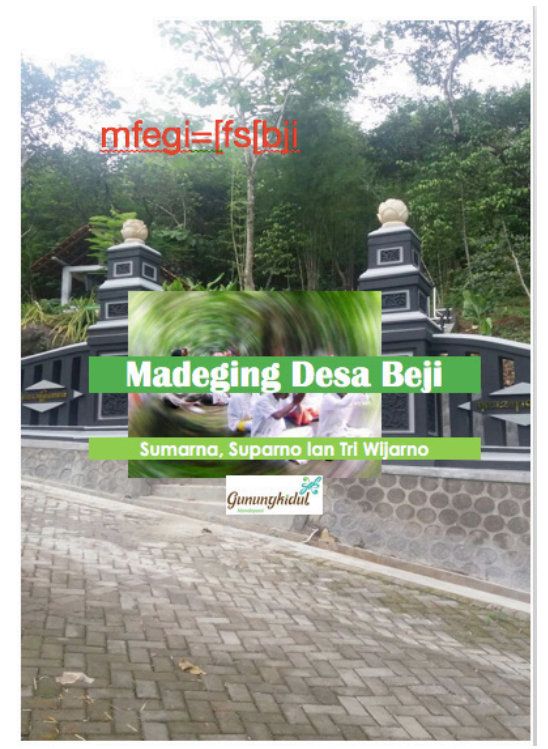

Gambar 1. Cover buku “Madeging Desa Beji”. Sumber: Dokumentasi pribadi.

\section{Inventarisasi Tokoh Desa}

Tim PkM melakukan dua kali perjalanan ke Desa Beji. Penulisan dan pendampingan tersebut dilakukan dua kali pada 4 Mei dan 15 Juli 2019. Pada pendampingan pertama, sifatnya adalah mengidentifikasi para tokoh potensial Desa Beji yang penting. Dalam pertemuan tersebut, teridentifikasi beberapa nama yang dapat dilakukan penulisan lebih lanjut. Mereka adalah Mbah Yatmo (ritual Sadran) yang beralamat di Sidorejo, 


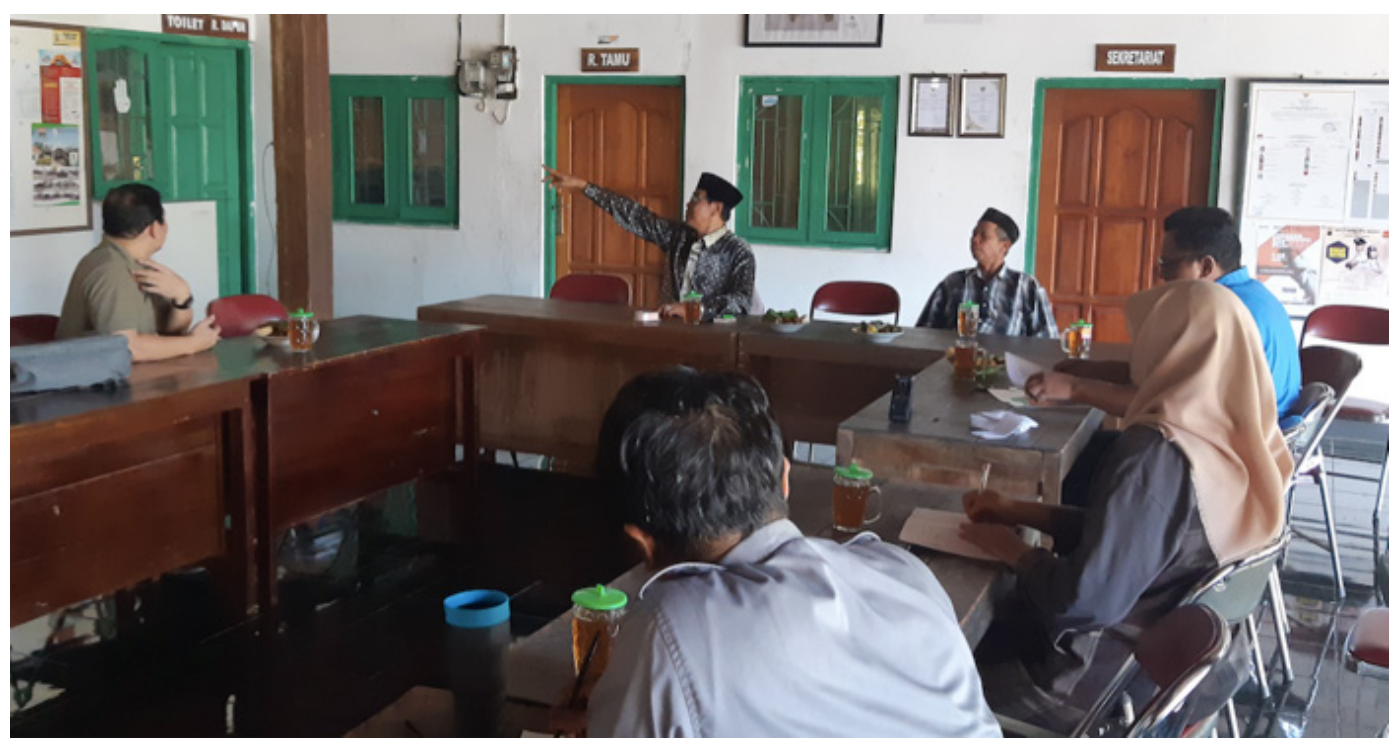

Gambar 2 Inventarisasi tokoh Desa Beji. Sumber: Dokumentasi pribadi.

Bapak Harno Sumiyo (dalang ruwat) yang beralamat di Daguran, Mbah Gito di Duren, Bapak Sukarman Thoklek (seniman tari), Bapak Triman (ulama), dan Bapak Kardi. Kesemuanya mempunyai potensi untuk dibuatkan sejarah mengenai keluarga mereka.

Penulisan tokoh-tokoh tersebut secara mendalam tentu dibutuhkan waktu yang sangat panjang dan berkelanjutan. Mempertimbangkan waktu yang tidak memungkinkan, tim memutuskan untuk melakukan wawancara mendalam terhadap satu orang saja dan kemudian menuliskannya sebagai satu contoh penulisan yang kemudian bisa dilakukan di dalam PkM. Tokoh tersebut adalah Mbah Yatmo, pembaca doa dalam tradisi Sadranan.

\section{Refleksi Capaian Program}

\section{Menyusun Ingatan Masa Lalu Mbab Yatmo tentang Keluarga dan Sadranan}

Tradisi Sadranan merupakan tradisi sakral yang terus dipelihara dari generasi ke generasi dalam kehidupan masyarakat Desa Wonosadi. Melalui tradisi tersebut, masyarakat Beji menunjukkan kepatuhannya sebagai bagian dari penduduk desa, sekaligus sebagai bagian dari cara mereka mewujudkan rasa syukur atas semua berkah yang diterima dalam jangka waktu setahun. Selanjutnya, mereka juga memberikan sesaji untuk memohon perlindungan agar dalam setahun ke depan masyarakat Desa Beji juga diberikan keberkahan dan kesejahteraan yang sama.

Satu tokoh yang kemudian menjadi sangat penting dalam tradisi Sadranan adalah pembaca doa. Dalam hal ini, hanya orang tua yang memiliki kemampuan mistis tertinggi lah yang kemudian mendapatkan kesempatan sebagai pembaca doa. Mbah Yatmo-lah orang yang sejak beberapa tahun ini dipilih sebagai pembaca doa, yang berperan sebagai penghubung ikatan masyarakat adat Beji dengan para pendahulu. Dengan demikian, peran Mbah Yatmo dalam tradisi Sadranan menjadi sangat penting.

Saat ini, usia Mbah Yatmo adalah sekitar 70 tahun. Mbah Yatmo sendiri tidak tahu secara persis tanggal, bulan, dan tahun kelahirannya sehingga tidak mampu memastikan 
usia pasti dirinya. Mbah Yatmo saat ini tinggal di Desa Beji bersama anak ketiganya. Sebenarnya, kemampuan Mbah Yatmo sebagai pembaca doa-doa dalam prosesi Sadranan bukanlah sesuatu yang ia dapatkan secara turun-temurun. Ayah Mbah Yatmo bahkan bukan merupakan pembaca doa, melainkan seorang petani biasa. Akan tetapi, hal itu karena kemampuan spiritual Mbah Yatmo dalam berinteraksi dengan "leluhur" serta usia Mbah Yatmo yang relatif paling tua di antara para sesepuh desa saat itu sehingga sejak lima tahun ke belakang, Mbah Yamto ditunjuk sebagai pembaca doa pada saat tradisi Sadranan.

Sebelum Mbah Yatmo ditunjuk sebagai pembaca doa, yang dikenal sebagai pembaca doa adalah berturut-turut berikut ini. Pertama adalah Mbah Nur. Ia merupakan pembaca doa paling senior yang diingat olah Mbah Yatmo. Sebelum Mbah Nur menjadi pembaca doa, menurut Mbah Yatmo, pembacaan doa tidak pernah dilakukan di Desa Beji. Latar belakang Mbah Nur terpilih sebagai pembaca doa juga tidak mampu dijelaskan oleh Mbah Yatmo. Sepeninggal Mbah Nur, pembaca doa selanjutnya berturut-turut digantikan oleh Mbah Wongso, Mbah Karno, dan baru Mbah Yatmo.

Walaupun begitu, urutan pembaca doa tersebut terjadi regenerasi kemampuan. Menurut Mbah Yatmo, tidak ada pelatihan khusus kepada para pembaca doa sebelum mereka diangkat menjadi pembaca doa. Hanya, karena mereka yang telah menjadi pembaca doa selalu mengikuti tradisi tersebut dari tahun ke tahun, mereka yang kemudian ditunjuk sebagai pembaca doa sudah memiliki bekal yang dianggap cukup untuk melakukan tugas-tugas tersebut.

Tugas yang harus dijalankan oleh seorang pembaca doa adalah melakukan ritual "Pasrah Panggang" dan "Sajen”. Artinya, setelah barang-barang yang sudah dikumpulkan oleh warga masyarakat dari semua dusun dan dibawa ke suatu tempat yang dikenal dengan nama bekas petilasan Loro Semi, para pembaca doa akan berdoa secara khusuk dengan disaksikan oleh seluruh masyarakat desa yang hadir dan selanjutnya Mbah Yatmo sebagai perantara akan membacakan doa agar keselamatan serta kesejahteraan desa dapat terus terjaga.

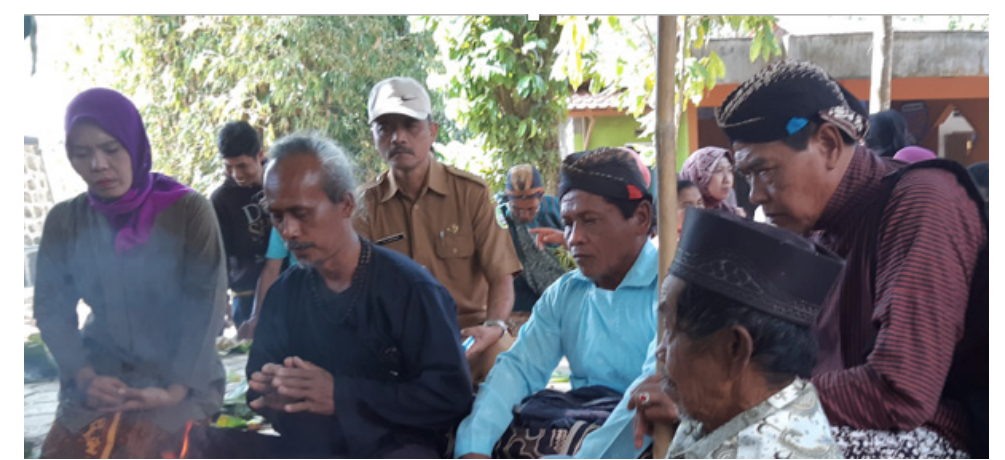

Gambar 3. Foto Mbah Yatmo ketika mengikuti prosesi Sadranan. Sumber: Dokumentasi pribadi.

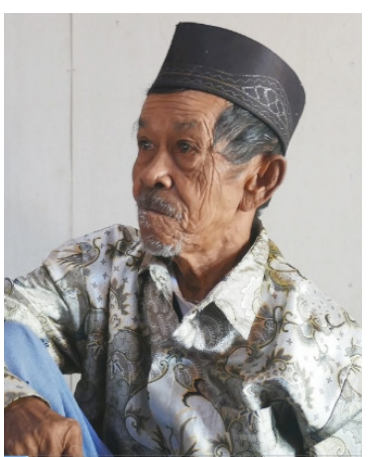

Gambar 4. Mbah Yatmo memberikan informasi tentang keluarga dan tradisi Sadranan. Sumber: Dokumentasi pribadi. 


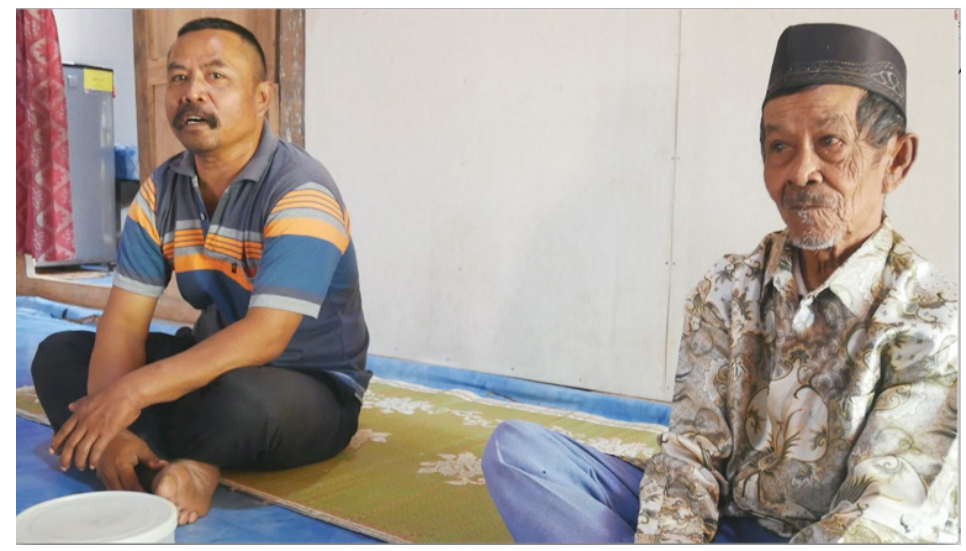

Gambar 5. Mbah Yatmo dan putranya. Sumber: Dokumentasi pribadi.

Mbah Yatmo memiliki 6 orang anak. Mereka rata-rata bekerja sebagai petani dan beberapa di antaranya adalah para pemelihara seni di Desa Beji. Untuk masyarakat Beji, pemeliharaan seni secara turun-temurun merupakan satu kebutuhan yang tidak boleh mereka tinggalkan. Tak heran jika setiap dusun di Beji memiliki dan terus memelihara kesenian di dalam kehidupan sehari-hari mereka.

\section{Penutup}

PkM yang dilakukan oleh tim pengabdian Departemen Sejarah FIB telah menghasilkan langkah penting berupa terjalinnya komunikasi dan kedekatan emosional antara UGM sebagai perguruan tinggi dan masyarakat Beji sebagai sebuah kawasan pengabdian. Dalam pertemuan yang dilakukan dihasilkan sebuah langkah penting berupa dihasilkannya contoh penulisan sejarah keluarga, dalam hal ini keluarga Mbah Yatmo, yang bisa dilakukan. Pengabdian seperti ini dapat diteruskan dalam waktu-waktu berikutnya seiring dengan pentingnya mendekatkan dunia perguruan tinggi dengan masyarakat tempatan.

\section{Daftar Pustaka}

Amini, M. dkk. (2017). “Masa Lalu untuk Masa Kini: Sejarah Desa Beji”. Dalam Laporan Pengabdian kepada Masyarakat UGM.

Ibrahim, J. (2012). “Goncangan pada Keselarasan Hidup di Kasultanan”. Dalam Taufik Abdullah dkk., Malam Bencana 1965 dalam Belitan Krisis Nasional Bagian II Konflik Lokal. Jakarta: Yayasan Obor Indonesia.

Laksono, P.M. dkk. (2009). "Wonosadi, Sebuah Dinamika Pengelolaan Hutan Rakyat". Dalam Laporan Penelitian kerja sama Yayasan Kehati dan Pusat Studi Asia Pasifik UGM.

Purwanto, B., Saptari, R., dan Nordolt, H.S. (2008). Perspektif Baru Penulisan Sejarah Indonesia. Jakarta: KITLV dan Yayasan Obor Indonesia.

Sulistyowati. (2015). "Bahasa Jawa Masyarakat Tutur Enklave Surakarta di Yogyakarta: Kajian Etno-Linguistik”. Disertasi. Yogyakarta: Program Ilmu-Ilmu Humaniora UGM. 